Teaching \& Learning (2020/2021), 13(1), 1-12

\title{
Instructor-featured Videos and the Importance of Social Presence in Online Education
}

\author{
AARON SMITH \\ University of Waterloo
}

\begin{abstract}
The recent global shift to online teaching has thrust educators in all levels and forms of education into new roles and experiences. As many have little prior experience teaching online, it is possible that there are those who feel overwhelmed, and as such focus on technical aspects of online education. By reviewing the concept of social presence in online education, this paper seeks to accomplish two tasks: first, to remind readers of the importance of interpersonal aspects of online education; and second, to recommend instructor-featured videos as an accessible and effective way of fostering social presence and helping students feel grounded, connected, and reassured.
\end{abstract}

\section{Introduction}

The COVID-19 global pandemic has produced many changes and challenges to learning institutions throughout the world. As educators, researchers, and administrators alike have struggled to adjust policies and practices, various organizations have provided commentary on these struggles. For example, in an April 2020 edition of the International Association of Universities' Newsletter, it is observed:

Leaders of the universities and academic staff around the world are working tremendously hard to lessen the disruption of learning and research and to ensure that their universities continue to carry out operations despite the lock-down measures. This requires fast responses, innovating thinking and teamwork. (para. 2)

Although this and similar statements contain no formal recommendations regarding how to "carry out operations despite the lock-down measures," an overwhelming majority of learning institutions throughout the world have moved to a near-exclusive online format of course delivery. Though it remains to be seen how long this will continue or what the lasting effects will be, one thing remains clear - educators across every discipline and every level of education have been required to teach online. 
The shift to online education is understandable given its many benefits. These include, for example, increased accessibility to students (Forgey \& Ortega-Williams, 2016) and the flexibility to offer content in a variety of synchronous and asynchronous formats (Oztok, Zingaro, Brett, \& Hewitt, 2013). Perhaps the greatest perceived benefit of online education is that it is a readily available and a relatively easy method to simply keep teaching (Lederman, 2020).

Despite its popularity and benefits, however, numerous limitations are inherent in online education. These include, for example, difficulties maintaining students' attention (Lee, 2020) and "the potential lack of interpersonal interaction between instructors and students" (Jones, 2015, p. 226). Further, many instructors, particularly those new to online education, tend to feel overwhelmed by the technology, and thereby focus on the many technical aspects of teaching online (Aitken \& Loads, 2019). This paper, then, seeks to accomplish two goals: first, to remind educators of the importance of "interpersonal interaction between instructors and students" (Jones, 2015, p. 226); and second, to recommend the use of instructor-featured videos as a means of fostering social presence in online education.

\section{Social Presence}

Social presence, which "refers to the extent to which persons are perceived to be real and are able to be authentically known and truly connected to others" (Bentley et al., 2015, p. 494), is considered by many to be a crucial concept in the realm of education (e.g., Aragon, 2003; Bentley et al., 2015; Cobb, 2009). First introduced by Short, Williams, and Christie (1976), social presence requires two concepts: immediacy and intimacy. Behaviours associated with immediacy include a variety of verbal and nonverbal actions, such as responding frequently and personally, using humour, and demonstrating attentiveness (Baker, Maben, \& Edwards, 2015). Intimacy, likewise, involves both verbal and nonverbal actions, such as self-disclosure, physical proximity, and eye contact (Cobb, 2009). When these and similar actions are consistently demonstrated by an instructor in a teaching and learning environment, whether online or inperson, they tend to increase levels of student satisfaction (Bentley, Secret, \& Cummings, 2015). They also tend to increase student participation and engagement with both each other and the material itself (Paquette, 2016). 
The impact of social presence in education is not limited to measurable outcomes, but also to less tangible, yet equally important effects. Aragon (2003), for example, notes that social presence tends to produce increased feelings of comfort. Rourke, Anderson, Garrison, and Archer (1999) suggest that social presence creates a sense of warmth, collegiality, approachability, and closeness. Paquette (2016) likewise suggests that interjecting social presence into an online course can "change the entire atmosphere of a course" (p. 80).

\section{The Need for Social Presence in Online Education}

As mentioned above, a common experience of online education is the experience of interpersonal disconnect. This limitation has been reported by students (Oztok et al., 2013) and instructors (Levin, Fulginiti, \& Moore, 2018) alike. Further, this limitation has been identified as one of the biggest challenges in online education (Dumford \& Miller, 2018; Jones, 2015).

To effectively create social presence requires more than the "simple 'onlinification' of face-to-face lectures" (Lee, 2020, para. 7). It requires "intensive instructor presence in frequent, consistent, and highly responsive interaction with students and a variety of structured and wellfacilitated opportunities for student interactions" (Jones, 2015, p. 233). Given the recent shifts to online education experienced by educators throughout the world, however, it stands to reason that "most academics will record their lectures using a webcam and the same slides from previous face-to-face teaching" (Lee, 2020, para. 7), in particular those who have never taught in an online format. While this may be necessary in some situations, it is far from ideal.

A recent study (Aitken \& Loads, 2019) revealed that the experience of instructors new to online teaching is often one of extreme adjustment. One instructor interviewed in this study, for example, provided an apt description of this experience: "I found it quite disorienting at first to have the multiple streams of communication going on...that's a hell of a lot to be going on at the same time" (p. 39). As a result, it is not uncommon for instructors in these situations to focus on the technical more than the social aspects of the course. Understandable though this may be, at the best of times online students tend to experience feelings of isolation (Dumford \& Miller, 2018; Lee, 2020), loneliness (Jones, 2015), and disconnect (Baker et al., 2015). For those less experienced in online teaching, it is possible that by focusing on technical rather than social dimensions of a course, they may unintentionally create the sort of climate that increases the risk 
of students feeling such emotions. It is suggested, however, that social presence is an effective way to help counter such feelings of disconnect (Bentley et al., 2015).

\section{Strategies to Foster Social Presence}

The practice of fostering social presence can occur in different ways and at different times throughout an online course. For example, some strategies can be employed before the course even begins, when one is in the process of designing or redesigning the course (Baker et al., 2015), and others can be used throughout a course as it is occurring in real time.

Literature abounds with strategies for creating and maintaining social presence in the context of online education. For example, the following are but a few strategies suggested:

- Creating and posting a text-, audio-, or video-based welcome message (Aragon, 2003)

- Answering and encouraging students to likewise answer icebreaker sorts of questions (Bentley et al., 2015)

- Checking with students on a semi-regular basis either through email, phone, or another telecommunication means such as video conferencing (Baker et al., 2015)

- Providing audio and/or video feedback to assignments as opposed to simply textbased feedback (Borup et al., 2012)

- Encouraging and even modelling personal reflection and disclosure through stories (Aragon, 2003), thoughts on course material (Bentley et al., 2105), or providing personal or professional background information (Paquette, 2016)

- Actively contributing to student discussion boards (Aragon, 2003)

- Using language such as we or $u s$ which can suggest both a sense of joint ownership and a shared space (Paquette, 2016).

Wise, Chang, Duffy, and Del Valler (2004) likewise suggest that increasing the level of social presence involves a number of cues: expressing humour; demonstrating emotions; using selfdisclosure; complimenting or showing support or agreement for another's idea; addressing people by name; using verbal and non-verbal forms of greeting and phatic communication; and using language meant to give the allusion of physical presence, such as "today in class" or " $I$ really enjoyed our time together" (Paquette, 2016). Perhaps the most commonly referenced 
method for fostering social presence in an online course format is that of instructor-featured videos (e.g., Aragon, 2003; Baker et al., 2015; Borup et al., 2012; Jones, 2015; Jones-Roberts, 2018).

\section{Instructor-featured Videos as a Means for Fostering Social Presence}

As demonstrated above, with the spread of COVID-19 and the decision for educational institutions to move the majority of their course offerings to an online format, it is highly likely that many instructors throughout the world have recently found themselves in a position in which they are required to teach - perhaps for the first time - online. It is also highly likely that many of these instructors have neither the time, resources, nor experience to design or redesign courses with the goal of creating social presence. The use of instructor-featured videos is thus recommended as a means for easily and quickly fostering social presence.

Though the process of streaming or uploading videos was at one point a technological challenge and therefore not easily available to all online instructors (Aragon, 2003), in recent years numerous software and other online applications such as YouTube and Vimeo, to name just two, have made the use of instructor-created videos to meet student learning needs much more possible. Additionally, it has been rated as one of the most effective teaching methods in online education (Forgey \& Ortega-Williams, 2016). Between its ease of use and its proven effectiveness, there is now more reason than ever for instructors to use this particular strategy in online teaching. It is worth noting that given the lingering concerns and fears some instructors have about online education (Aitken \& Loads, 2019; Levin et al., 2018), it is likely that there are those who are likewise reticent about attempting to employ videos. Jones-Roberts (2018) reminds all of us, however, that online videos do not need to be complicated: "Instructor video can be as simple as a course introduction, instructional videos, weekly check-in videos, individual or group webconferences" (Jones-Roberts, 2018, p. 48). Yet another helpful reminder, as noted by Aitken and Loads (2019), is that "all of that [technology] doesn't matter, or whether you are in the same room as people physically, it's about the relationship you have with people" (p. 40). In other words, students are less concerned about how instructors go about creating social presence as they are about knowing that their instructor is a real person who cares about them and their learning (Borup et al., 2012). 


\section{Impacts of Instructor-featured Videos on Students}

As an instructor who has taught in varying levels and formats of education for nearly a decade, including face-to-face, online, and blended modalities, I have witnessed firsthand the importance and impact of social presence. For the past several years, I have taught one particular online course that is comprised of students who are in the process of completing practica across numerous time zones and in all regions of Canada. Further, this course is organized in such a manner that start- and end-dates vary by student. Due to these variables, the course is structured in an asynchronous format which, as Hrastinski (2008) notes, can increase feelings of isolation as compared to synchronous learning.

Though my approach to fostering a sense of social presence in online teaching has included a variety of methods, such as participating in student discussion boards (Aragon, 2003) and always referring to students by their names (Paquette, 2016), the primary method I have used is instructor-featured videos. These videos have been filmed in a variety of locations, such as my office, my home, and even my car. I have most often used a smartphone for these recordings and have uploaded them to Vimeo or YouTube before posting a link to the course page.

As the name suggests, these instructor-featured videos have featured little more than myself, and have been used for several reasons including course introductions, check-ins, and various instructional videos. In these videos I have disclosed information about my personal life, discussed my professional work, gone "on location" to various areas when discussing certain subjects, and even read from my young daughters' story books as a means of explaining and supplementing course content. I have also posted numerous videos to check in with students, to reassure students, and to validate students during challenging times, such as at the start of the course, at busy times throughout the year, and in the wake of difficult events such as the changes brought about as a result of the COVID-19 pandemic.

During the first several years that I taught this course, I heard little to no feedback from students about these videos. I was aware that they were watching them, as per analytic reports, but was unsure about the impact they were having. More recently, however, that changed as several students shared unsolicited feedback about the impact of these videos through online postings and emails. This feedback confirms that using videos was an effective means of fostering social presence in online learning. More specifically, using videos helped students feel grounded, connected, and reassured. 
Instructor-featured Videos

\section{Instructor-featured Videos as Grounding}

As explained by Daniels (2005), feeling "grounded" refers to having "a sense of being fully embodied, whole, centred and balanced in ourselves and in relationships” (p. 290). When one student wrote, "Your video check ins were very grounding and a saving grace at times," it is thus assumed that this particular student was experiencing factors such as stress or anxiety that threatened to disrupt this sense of being centered or balanced. Though this particular student did not identify which videos or what content in particular they found to be grounding, it is possible that seeing and hearing their instructor, instead of simply reading more text on a screen, helped re-center them. It is also possible that seeing and hearing their instructor validate the challenges they were experiencing and that it was okay to struggle was also very grounding.

Daniels' (2005) definition of grounded describes another aspect of the videos that the students may have found helpful: experiencing a sense of being whole. By acknowledging the normalcy and even appropriateness of feeling overwhelmed, disoriented, or otherwise struggling, and encouraging students to take care of themselves, may have helped remind students that they were more than students. For example, another student's feedback seems to confirm Daniels' description of grounding equating a sense of wholeness:

I really appreciated your candid, relatable video post. It honestly helped me a lot to hear from you in such a kind, thoughtful way. It helped me to have more compassion for myself during these strange times. Thank you so much.

For this student, the videos seem to have served as a reminder that they were more than a student; they were also a person who was allowed to struggle and who had permission to take care of their whole self.

\section{Instructor-featured Videos as Connecting}

A second way that the videos used throughout this course appear to have positively impacted students involves the interpersonal disconnect that is often associated with online education (Jones, 2015). One student wrote: “...regarding the comfort I took in the videos There is a big disconnect with online learning, in that we miss out on having many face-to-face conversations and opportunities of connection. Definitely was a nice check-in throughout the year!" Another responded to this comment: 
Sometimes online courses are hard to create personal connections and for students to feel supported. In the videos that the professor posted, I feel that he was able to connect with us on a personal level, while providing the support that we all need-especially now with all the COVID-19 aspects.

In a message sent directly to me, yet another student wrote:

I really enjoyed this course. More specifically, I really appreciated the videos you uploaded to connect with us, they really allowed us to get to know you and I know for me, I felt very supported overall. Having online courses, sometimes it is hard to connect with other students and the professors, however, I feel that you fostered a sense of connectedness and belonging.

Statements such as those listed above indicate several important concepts in the realm of online education. First, students do not always feel an interpersonal connection. Second, students crave an interpersonal connection, and third, videos can help to cultivate feelings of connection.

Jones-Roberts (2018) writes that "humans are inherently social creatures. Socialization and connection with a learning community is a central aspect of learning” (p. 47). Others likewise describe the importance of creating both social and emotional connections in online education (e.g. Baker et al., 2015; Bentley et al., 2015). As one student put it:

I wanted to let you know how much I enjoyed watching the videos that you created. It created a really nice connection and more 'human' approach to this course. I think that there should be more of those videos in our program - in my opinion, I often felt quite a disconnect between instructors and students. Your videos helped create a connection that wasn't otherwise there.

Feedback such as this suggests that posting informal videos throughout a course is an easy yet effective way to go about fostering the sense of connection that so many students crave.

\section{Instructor-featured Videos as Reassuring}

A third way in which videos positively impacted students is seen in the following statement by a student: 
What I loved most about this semester are the videos in this class. This may sound silly but being able to actually see the professor is reassuring in a way. Digital classrooms can feel so disconnected so I appreciated a chance to see the person on the other end.

Not only did this student find the videos helpful in creating a sense of connection, but also in feeling reassured that there was in fact a real person on the other side of the computer. If all students see is text on a screen, it is possible that they will not consciously think of their instructor as a "real person" (Bentley et al., 2015; Gunawardena, 1995). If, however, steps towards social presence such as uploading instructor-featured videos are taken, it increases the likelihood of the instructor being thought of as a flesh-and-blood person.

The simple act of posting videos of me showing a pack of M\&Ms when talking about self-care, reading one of my children's books, or simply discussing course material from my kitchen table helped to build a sense of familiarity. As students began to see that I am not merely an instructor, but also someone who likes M\&Ms, has children, and sometimes works in my kitchen, they began to feel reassured that I understood their world. I was not some academic in a distant ivory tower, but instead I was a normal human being. In other words, I was relatable. As one student put it:

I thoroughly enjoyed your video postings and their relevance during these strange times... mostly I appreciated your candidness. We are all in this together and I think I can speak for all of us when I say, you certainly made us feel this way.

Being relatable, in turn helped to reassure and foster a sense of trust (Borup et al., 2012).

\section{Other Positive Impacts}

The abovementioned positive impacts of instructor-featured videos are but three of the benefits of this approach to building and maintaining social presence. Feedback suggests that there are many other positive impacts as well. For example:

- " they [the videos] always made me smile and reengage with the course." 
- "of all the online classes I have taken over the last 6 years, the most successful and engaging classes I was in have been those where the instructor recorded videos...those courses and their content were much more memorable for me."

- "your videos were very much a refreshing change from other courses; it makes a difference. Thank you for taking the time to make them."

- "thank you for being so relatable and encouraging throughout the semester in your videos and your approach! I never felt the need to reach out throughout the semester, but I always felt welcomed to if needed!"

In addition to grounding, connecting, and reassuring, student feedback suggests that the videos were encouraging, refreshing, comforting, and supportive. The videos appeared to help me seem more relatable, accessible, and welcoming. They even helped students reengage with course material. In other words, instructor-featured videos were not only an accessible and easy-to-use tool to increase social presence, but also a highly effective way of doing so that has numerous positive impacts on students.

\section{Conclusion}

As mentioned at the onset of this paper, organizations throughout the world have posted various commentary and other statements about the continuance of education during the COVID19 pandemic. One such statement by the Council on Social Work Education (2020) reads, "Educators are encouraged to work with their institutions and community on appropriate contingency plans to continue to deliver quality education to social work students" (para. 1)". It does not say that educators are encouraged to deliver education in some broad, undefined manner. Instead, it says that educators are encouraged to deliver quality education to students specifically.

Though technical aspects of course design and delivery are certainly important, especially when one is teaching online, it is important to remember the dangers of an online classroom becoming purely "a repository of information" (Aitken \& Loads, 2019, p. 43). We must remember that students "need and want substantial interaction with their instructors...learners 
need connectivity to the instructor" (Noble \& Russell, 2013, p. 511). Students need and want to know "that there are real people who care about them and about their learning" (Wise et al., 2004, p. 249, emphasis added). In other words, we must remember that as important as technical aspects are, the way we interact with students is equally, if not more, important.

Social presence is a useful and essential concept when it comes to the design and delivery of online education. As Jones-Roberts (2018) notes, however, "ultimately, there is no singular strategy to increase online social presence" (p. 49). As such, though other strategies exist, instructor-featured videos are recommended as good of a practice as any, with which to begin. Not only is this practice easily and readily available, which will be of benefit for those who are new to online teaching, it is also one that will positively impact those we seek to teach.

Aaron Smith is an Instructor at Renison University College and King's University College, a Registered Psychotherapist at STAR Family Health Team, and the Director of Social Research and Education Group. Aaron has graduate degrees in Theological Studies and Spiritual Care \& Psychotherapy, and is a PhD Candidate in the Faculty of Social Work at Wilfrid Laurier University. Aaron's current research considers the experience of relational engagement in light of the intersecting nature of personal and professional identities.

\section{References}

Aitken, G., \& Loads, D. (2019). Experiences of staff new to teaching postgraduate students online: Implications for academic staff development. Journal of Perspectives in Applied Academic Practice, 7(1), 37-46.

Aragon, S. R. (2003). Creating social presence in online environments. New Directions for Adult and Continuing Education, 100, 57-68. https://doi.org/10.1002/ace.119

Baker, C., Maben, S., \& Edwards, J. (2015). Strategies for establishing and sustaining social presence in the online learning environment. In R. D. Wright (Ed.) Student-teacher interaction in online learning environments (pp. 251-265). Hershey, PA: IGI Global.

Bentley, K. J., Secret, M. C., \& Cummings, C. R. (2015). The centrality of social presence in online teaching and learning in social work. Journal of Social Work Education, 51(3), 494-504.

Borup, J., West, R., \& Graham, C. (2012). Improving online social presence through asynchronous video. The Internet and Higher Education, 15(3), 195-203. https://doi.org/10.1016/j.iheduc.2011.11.001

Cobb, S. C. (2009). Social presence and online learning: A current view from a research perspective. Journal of Interactive Online Learning, 8(3), 241-254.

Council on Social Work Education. (2020). CSWE responding to COVID-19. Retrieved July 9, 2020 from https://cswe.org/News/CSWE-Compass/CSWE-Compass-March-2020

Daniels, M. (2005). Shadow, self, spirit: Essays in transpersonal psychology. Charlottesville, VA: Imprint Academic. 
Dumford, A. D., \& Miller, A.L. (2018). Online learning in higher education: Exploring advantages and disadvantages for engagement. Journal of Computing in Higher Education, 30, 452-465. https://doi.org/10.1007/s12528-018-9179-z

Forgey, M. A., \& Ortega-Willians, A. (2016). Effectively teaching social work practice online: Moving beyond can to how. Advances in Social Work, 17(1), 59-77.

Gunawardena, C. N. (1995). Social presence theory and implications for interaction and collaborative learning in computer conferences. International Journal of Educational Telecommunications, 1(2/3), 147-166.

Hrastinski, S. (2008). Asynchronous and synchronous e-learning. Educause Quarterly, 31(4), 5155.

International Association of Universities. (2020, April). The Global Voice of Higher Education. Retrieved April 20, 2020, from http://sh1.sendinblue.com/agyr5stpf9t7e.html?t=1586428153

Jones, S. H. (2015). Benefits and challenges of online education for clinical social work: Three examples. Clinical Social Work Journal, 43, 225-235.

Jones-Roberts, C. (2018). Increasing social presence online. Distance Learning, 15(2), 47-50.

Lederman, D. (2020, March 18). Will shift to remote teaching be boon or bane for online learning? Inside Higher Ed. Retrieved July 9, 2020, from https://www.insidehighered.com/digital-learning/article/2020/03/18/most-teaching-goingremote-will-help-or-hurt-online-learning

Lee, K. (2020, March 9). Coronavirus: Universities are shifting classes online - but it's not as easy as it sounds. The Conversation. Retrieved April 4, 2020, from http://theconversation.com/coronavirus-universities-are-shifting-classes-online-but-itsnot-as-easy-as-it-sounds- 133030

Levin, S., Fulginiti, A., \& Moore, B. (2018). The perceived effectiveness of online social work education: Insights from a national survey of social work educators. Social Work Education, 37(6), 775-789. doi: 10.1080/02615479.2018.1482864

Noble, D., \& Russell, A. C. (2013). Research on webbed-connectivity in a web-based learning environment: Online social work education. Journal of Teaching in Social Work, 33(4/5), 496-513.

Oztok, M., Zingaro, D., Brett, C., \& Hewitt, J. (2013). Exploring asynchronous and synchronous tool use in online courses. Computers \& Education, 60(1), 87-94. https://doi.org/10.1016/j.compedu.2012.08.007

Paquette, P. (2016). Instructing the instructors: Training instructors to use social presence cues in online courses. Journal of Educators Online, 13(1), 80-108.

Rourke, L., Anderson, T., Garrison, D. R., \& Archer, W. (1999). Assessing social presence in asynchronous text-based computer conferencing. Journal of Distance Education, 14(2), $50-71$.

Short, J., Williams, E., \& Christie, B. (1976). The social psychology of telecommunications. New York, NY: Wiley.

Wise, A., Chang, J., Duffy, T., \& Del Valle, R. (2004). The effects of teacher social presence on student satisfaction, engagement, and learning. Journal of Educational Computing Research, 31(3), 247-271. 